\title{
Improved Global Maximum Power Point Tracking Method Based on Voltage Interval for PV Array under Partially Shaded Conditions
}

\author{
Kun Ding ${ }^{\dagger}$, Xiang Wang ${ }^{*}$, Quan-Xin Zhai ${ }^{*}$, Jun-Wei Xu', Jing-Wei Zhang ${ }^{*}$, and Hai-Hao Liu ${ }^{*}$ \\ $\dot{\dagger}^{*}$ College of Mechanical \& Electrical Engineering, Hohai University, Jiangsu, China
}

\begin{abstract}
The power-voltage $(P-V)$ curve of photovoltaic (PV) arrays connected in parallel to bypass diodes would have several local maximum power points (LMPP) under partial shading conditions (PSC). Conventional maximum power point tracking (MPPT) methods fail to search for the global maximum power point (MPP) because the searched peak point may remain at the LMPP on the $P-V$ curve under PSC. This study proposes an improved MPPT algorithm to ensure that PV arrays operate at global maximum power point (GMPP) under PSC. The proposed algorithm is based on a critical study and a series of observations of PV characteristics under PSC. Results show the regularity of voltage interval between LMPPs. The algorithm has the advantages of rapidly reaching GMPP, maintaining stability, and recovering GMPP quickly when the operating condition changes. Simulation and experimental results demonstrate the feasibility of the proposed algorithm.
\end{abstract}

Key words: Global maximum power point tracking (GMPPT), Partially shaded conditions (PSC), PV array, $P-V$ curve, Voltage interval

\section{INTRODUCTION}

The operating conditions of photovoltaic (PV) power generation system are complicated. Maximum power point tracking (MPPT) is essential to enhance system effectiveness and achieve the maximum output power because of the nonlinear characteristics of PV arrays. Many MPPT methods have recently been proposed and implemented to optimize the output power of PV systems. Numerous conventional methods promote such efficiency and reach the maximum power point (MPP) quickly. These methods include the fractional open-circuit voltage method [1], perturb and observe method (P\&O) [2], [3], hill-climbing, incremental conductance (INC) method [4], and fuzzy logic control search method [5]. These traditional methods are mature and widely used under uniform conditions.

However, PV array characteristics become complicated

Manuscript received Oct. 20, 2013; accepted Apr. 29, 2014

Recommended for publication by Associate Editor Yujin Song.

'Corresponding Author: dkhhu@163.com

Tel: +86-519-85191951, Fax: +86-519-85120010, Hohai University

${ }^{*}$ College of Mechanical \& Electrical Engineering, Hohai University, China under various conditions, such as PV modules with different irradiances and temperatures, mismatch, and shading patterns. Many researchers have demonstrated power decreases caused by shadows [6]-[8]. Conventional MPPT methods become invalid under these conditions because power-voltage $(P-V)$ characteristics become more complex and display multiple local maximum power points (LMPPs) [9]. The peak power of a module would significantly decrease with the slightest shading of the module, and this effect is propagated through other modules with non-uniform irradiances connected in series and parallel to the shaded ones. With traditional methods P\&O and INC, the MPP would stay at an LMPP point other than the global maximum power point (GMPP). The methods mentioned above cannot track GMPP accurately and quickly if partial shading conditions (PSC) occur frequently. Several novel methods have been proposed to increase the reaching speed and stability of searched GMPP under PSC. Control and circuit techniques are divided into four categories to mitigate the influence of PSC [10]. Modified MPPT techniques are used to detect GMPP, different array configurations for interconnecting PV modules, various PV system architectures, and different converter topologies appropriately. Particle 
Swarm Optimization (PSO) is used to track GMPP for extreme environmental conditions and large fluctuations of insolation and PSC, as well as to reduce oscillation once the GMPP is located [11], [12]. However, the PSO method requires user experience and initial input data optimization. Several two-stage methods working on MPP under PSC have been proposed [13]-[15].The two-stage MPP method with instant online measurement of $V_{\mathrm{OC}}$ and $I_{\mathrm{SC}}$ was utilized in [13]. This method is applied when values of $V_{\mathrm{MPP}}$ and $I_{\mathrm{MPP}}$ are $80 \%$ and $90 \%$ of $V_{\mathrm{OC}}$ and $I_{\mathrm{SC}}$, respectively. An additional circuit for instant online measurement is required and thus results in more complicated circuitry. Repeated measurements would also increase energy loss. To reach GMPP more rapidly, some load line-based methods have been proposed [13], [14].The load line method is a two-stage method based on load line regulation to search for GMPP [13]. In the first pattern, the operating point moves toward the vicinity of GMPPT on the load line $R_{\mathrm{PM}}=V_{\mathrm{PM}} / I_{\mathrm{PM}} . V_{\mathrm{PM}}$ and $I_{\mathrm{PM}}$ are the MPP voltage and current of PV array, respectively, under standard test conditions (STC). In the second pattern, the operating point converges to the actual GMPP. However, the author did not provide the principle of this method, which is therefore not applicable to all PSCs. The load line method is based on the characteristics of $I-V$ curves in [14]. The theory behind this method, as proposed in [14], was not stated, and the experiments the paper implemented were insufficient. Fibonacci search method is proposed in [15]. This method is fast and accurate, but the system is complex. This study only provided verification under certain confined conditions.

Patel and Agarwal proposed a GMPPT search algorithm with revised voltages of LMPPs in [16]. With certain critical observations on the $I-V$ and $P-V$ curves of partially shaded arrays, the authors found that voltages of LMPPs $(A, B, C, D, E$, and $F$ ) are in the vicinity of multiple of $80 \% V_{\mathrm{OC}}$ in one bypass diode area (the area of several solar cells parallel to a diode), as shown in Fig. 1.

A revised algorithm was proposed to search for GMPP under PSC depending on the relationship of voltages between LMPPs. The LMPPs are searched accurately by using the P\&O search method. The GMPPT search algorithm starts when the operating condition changes. The algorithm is executed with a reference voltage, the first LMPP $(A)$ is searched, and the values of voltage and power are stored, as shown in Fig. 1. The initial disturbance is toward the left side of the searching point. A disturbance is operated to search for the next successful LMPP. The slope $\mathrm{dP} / \mathrm{dV}$ is measured to assess whether the searched LMPP exists in the vicinity of a new operating point. The disturbance on the left side continues up to the lowest voltage, in which the GMPP would not occur. The search algorithm operating toward the left direction disturbance continues until $85 \%$ of the $V_{\mathrm{OC}}$ of PV array is reached. After all LMPPs have been searched and the values of their voltage and power are stored and compared for update, the GMPP is found.

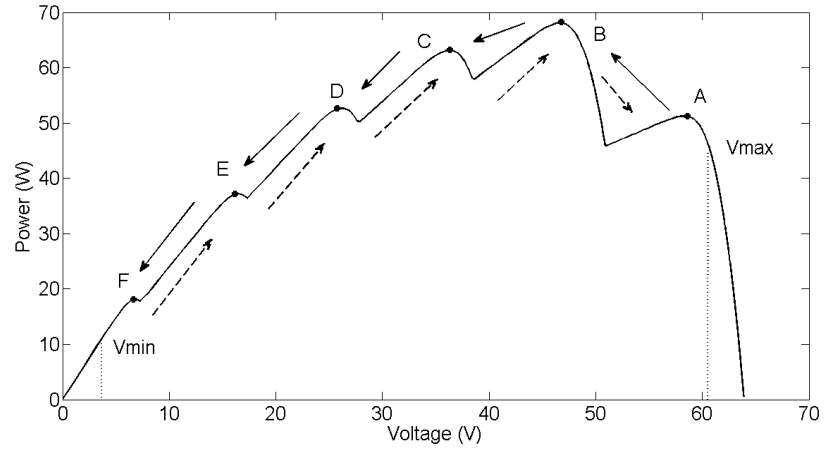

Fig. 1. Relationship of voltages between LMPPs.

This algorithm searches GMPP without scanning the entire $P-V$ curve, and the disturbance of GMPP tracking repeated twice can reduce the risk of missing the GMPP. This GMPPT algorithm is accurate and effective, but with some drawbacks. The algorithm executes both left- and right-side search, which is time consuming. The operating point cannot be assessed accurately if it is extremely close to the LMPP after disturbance. Thus, this point would have to be searched twice in the left and right side movements. Moreover, the disturbance between two adjacent LMPPs can only be assessed as the voltage is in transit and cannot be determined through deduction. Thus, the disturbance between two adjacent LMPPs can be confirmed more precisely.

This study presents the principle of voltage interval (the disturbance between two adjacent LMPPs) under PSC, according to the mathematical formula derivation of a mismatch model in the PV module, to improve the methods mentioned above. With this principle, the proposed algorithm can tract GMPP effectively under PSC. The search process starts from the rightmost side and every possible LMPP is searched once, thereby reaching the GMPP faster. The searching step that depends on the voltage interval algorithm is proposed in this study to ensure the searching point stays on the left within the vicinity of LMPP. The fine search algorithm for each LMPP is based on the P\&O method and thus remains stable at GMPP.

The remainder of this paper is organized as follows: Section II presents a series of observations and a critical study under PSC, and describes the principle of improved GMPPT algorithm. Section III demonstrates the flow of GMPPT and its detailed operating process. Section IV presents the simulation and experimental results.

\section{PRINCIPLE OF THE PROPOSED GMPPT ALGORITHM}

\section{A. Observations of Multiple LMPPs under PSC}

A PV module consists of solar cells connected in series; the modules are also connected in series and parallel to form a PV array. The characteristics of a PV module are based on solar cells [19]. The simulation model utilized in this study was 
TABLE I

PV MOdUle PARAMETERS

\begin{tabular}{lll}
\hline \hline Parameter & Symbol & Value \\
\hline Maximum power & $P_{\mathrm{MPP}}$ & $50 \mathrm{~W}$ \\
MPP voltage & $V_{\mathrm{MPP}}$ & $17.98 \mathrm{~V}$ \\
MPP current & $I_{\mathrm{MPP}}$ & $2.77 \mathrm{~A}$ \\
Short-circuit current & $I_{\mathrm{SC}}$ & $3 \mathrm{~A}$ \\
Open-circuit voltage & $V_{\mathrm{OC}}$ & $22 \mathrm{~V}$ \\
Temperature coefficient of & $\alpha$ & $0.04 \% / \circ$ \\
$I_{\mathrm{SC}}$ & $\mathrm{C}$ \\
Temperature coefficient of & \multirow{2}{c}{$-0.33 \% / \circ$} \\
$V_{\mathrm{OC}}$ & $\beta$ & $\mathrm{C}$ \\
\hline \hline
\end{tabular}

TABLE II

PV MODULES WITH DifFERENT IRRADIANCE CONDITIONS

\begin{tabular}{lcccccc}
\hline \hline & PV & PV & PV & PV & PV & PV \\
\hline con1 & 1000 & 1000 & 1000 & 1000 & 1000 & 1000 \\
con2 & 1000 & 1000 & 1000 & 1000 & 1000 & 900 \\
con3 & 1000 & 1000 & 1000 & 1000 & 900 & 800 \\
con4 & 1000 & 1000 & 1000 & 900 & 800 & 700 \\
con5 & 1000 & 1000 & 900 & 800 & 700 & 600 \\
con6 & 1000 & 900 & 800 & 700 & 600 & 500 \\
\hline \hline
\end{tabular}

proposed in [20]. The PV module model presented in [20] has good predictability of general behavior under PSC. All parameters of the module are presented in Table I.

Bypass diodes are in parallel arrangement in the PV modules as a protective measure to avoid any hot spot effects and to improve the output of PV array under PSC. A PV string is formed by PV modules, and the output characteristics of the string are superposed by the characteristics of each module. The string has only one MPP in uniform condition because each module has the same output. The shaded PV module has a lower irradiance than the normal modules when PSC occurs. The $P-V$ curve of the PV string would show multiple LMPPs, depending on the number of shaded PV modules.

A simulation model is established by three modules, with each module is parallel to two bypass diodes, to verify the corresponding relation between different irradiance and PV array of LMPPs. The string has six bypass diode areas called PV1 to PV6 [20].

The relationship between irradiance and the characteristics of the $\mathrm{P}-\mathrm{V}$ curve is analyzed with simulation. The different temperatures of the modules caused by nonuniform irradiance can be neglected when these are at the same level. All temperatures are set to $25{ }^{\circ} \mathrm{C}$. Six different conditions and the simulation results are shown in Table II and Fig. 2, respectively, wherein con 1 to con 6 indicate conditions 1 to -6 , and the unit of irradiance is $\mathrm{W} / \mathrm{m}^{2}$.

Fig. 2 shows the number of LMPPs of $P-V$ curve corresponds to the number of different irradiance conditions

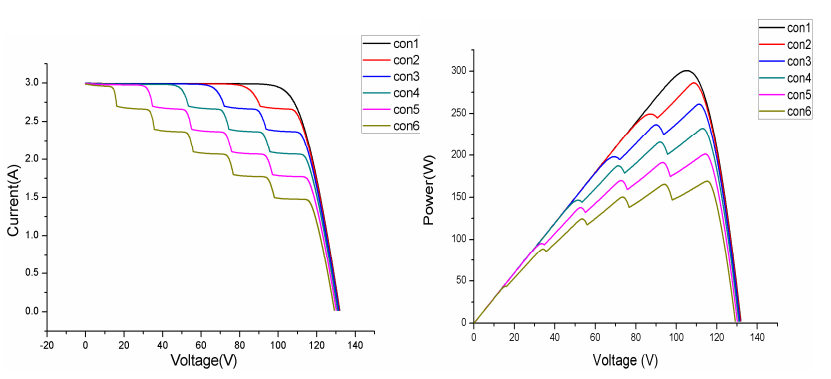

Fig. 2. Characteristics of different irradiance levels.

the array absorbed. For a PV string, the $I-V$ curve would display several knees and the $P-V$ curve shows several LMPPs with different intensity irradiance. The number of knees and LMPPs is in accordance with the number of different irradiance levels.

The characteristics of PV modules are the same when absorbing the same irradiance. Thus, modules with the same irradiance level would be divided into a group when the PV string operates under different irradiances. The number of LMPPs of the $P-V$ curve is in accordance with the number of separated groups.

\section{B. Mathematical Deduction of Voltage Interval between LMPPS}

To analyze the regulation of LMPPs and voltage interval in a PV string under PSC, the assumption is that three PV modules (PV1, PV2, and PV3) connect to a PV string and operate under different irradiance levels $(\mathrm{S} 1>\mathrm{S} 2>\mathrm{S} 3)$. The temperature of all the modules is assumed as the same value under STC. The specification of the simulation module model is presented in Table 1, and the different characteristics are shown in Fig. 3 (a) and (b).

This $I-V$ curve has three knees, and LMPPs from high to low voltage areas are called $C, B$, and $A$, as shown in Fig. 3(b).

A mathematical derivation is established in detail to analyze the above phenomenon.

A cell is defined as the semiconductor device that converts sunlight into electricity. The single-diode model is simple and sufficiently accurate in many cases [17], [18].

The $I-V$ equation of solar cell is

$$
I=I_{p h}-I_{d}\left\{e^{\frac{q\left(V+R_{S} I\right)}{A K T}}-1\right\}-\frac{V+R_{S} I}{R_{s h}}
$$

where $I_{0}$ is reverse saturation current of diode, $q$ is electron charge $\left(1.602 \times 10^{-19} \mathrm{C}\right), A$ is curve fitting factor, and $K$ is Boltzmann constant $\left(1.38 \times 10^{-23} \mathrm{~J} / \mathrm{K}\right)$.

Equation(1) is based on the most basic analytical expression of physical principle, widely used in theory analysis of solar cells. However, the five parameters $\left(I_{\mathrm{ph}}, I_{\mathrm{d}}, R_{\mathrm{sh}}, R_{\mathrm{S}}\right.$, and $\left.A\right)$ in the equation are influenced by the temperature of solar cells, which cannot be applied in engineering easily and are not provided by the manufacturers. 


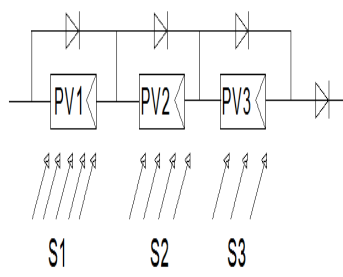

(a)

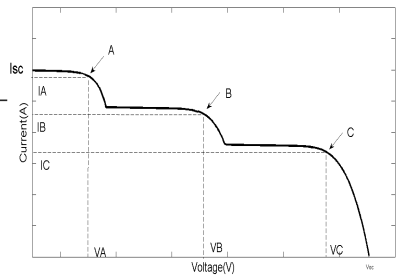

(b)
Fig. 3. Characteristics of different irradiance conditions with three modules.

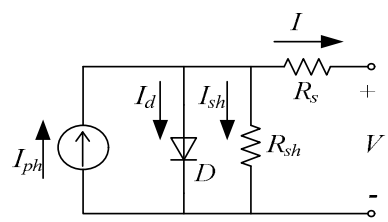

Fig. 4. Equivalent circuit of a single solar cell.

$I_{\mathrm{ph}}:$ photocurrent; $I_{\mathrm{d}}$ : current of parallel diode

$I_{\text {sh }}$ : shunt current; $I$ : output current; $V$ : output voltage

$D$ : parallel diode; $R_{\mathrm{sh}}$ : shunt resistance; $R_{\mathrm{S}}$ : series resistance

In [21], a new model for the PV module was proposed and proven effective and accurate. This model is set up with five technical parameters $\left(V_{\mathrm{OC}}, I_{\mathrm{SC}}, V_{\mathrm{M}}, I_{\mathrm{M}}\right.$, and $\left.P_{\mathrm{M}}\right)$ provided by the manufacturers only. Under STC, $V_{\mathrm{OC}}$ is open-circuit voltage, $I_{\mathrm{SC}}$ is short-circuit current, and $V_{\mathrm{M}}, I_{\mathrm{M}}$, and $P_{\mathrm{M}}$ are the voltage, current, and power of MPP. The relationship between voltage and current of the PV module is

$$
I=I_{S C}\left[1-C_{1}\left(e^{\frac{V}{C_{2} V O C}}-1\right)\right]
$$

In Eq. (2):

$$
\begin{array}{r}
C_{1}=\left(1-I_{M} / I_{S C}\right) e^{-V_{M} / C_{2} V_{O C}} \\
C_{2}=\left(V_{M} / V_{O C}-1\right) / \ln \left(1-\frac{I_{M}}{I_{S C}}\right)
\end{array}
$$

With consideration of the variation of irradiance and the influence of temperature, the relationship between voltage and current is

$$
\begin{gathered}
I=I_{S C}\left[1-C_{1}\left(e^{\frac{V-D V}{C_{2} V_{O C}}}-1\right)\right]+D I \\
V=C_{2} V_{O C} \ln \left(1+\frac{1}{C_{1}}\left(1-\frac{I-D I}{I_{S C}}\right)\right)+D V
\end{gathered}
$$

In [20], the calculation of $V_{\mathrm{OC}}$ under any given irradiance and temperature is proposed as

$$
V_{O C_{-} a n y}=V_{O C}\left(1+a * \ln \left(\frac{S}{S_{r e f}}\right)+\beta * D T\right)
$$

where $a$ is irradiance correction factor. Among Eq. (5), (6), and (7):

$$
\begin{gathered}
D I=\alpha \frac{S}{S_{r e f}} D T+\left(\frac{S}{S_{r e f}}-1\right) I_{S C} \\
D V=-\beta D T-R_{S} D I \\
D T=T-T_{r e f}
\end{gathered}
$$

where $\alpha$ is temperature coefficient of $I_{\mathrm{SC}}, \beta$ is temperature coefficient of $V_{\mathrm{OC}}, S_{\text {ref }}$ and $T_{\text {ref }}$ are irradiance and temperature under STC, and $R_{\mathrm{S}}$ is series resistance of PV module. The influence of $D T$ is ignored because the temperature is set as the same under STC.

The voltage of points $C, B$, and $A$ is shown as follows:

$$
\begin{aligned}
V_{C}= & V_{1_{-} C}+V_{2_{-} C}+V_{3_{-} C}-V_{d} \\
= & C_{2} V_{O C} \ln \left(1+\frac{1}{C_{1}}\left(1-\frac{I_{C}-D I_{1}}{I_{S C}}\right)\right)+D V_{1} \\
& +C_{2} V_{O C} \ln \left(1+\frac{1}{C_{1}}\left(1-\frac{I_{C}-D I_{2}}{I_{S C}}\right)\right)+D V_{2} \\
& +C_{2} V_{O C} \ln \left(1+\frac{1}{C_{1}}\left(1-\frac{I_{C}-D I_{3}}{I_{S C}}\right)\right)+D V_{3} \\
& -V_{d}
\end{aligned}
$$

where $V_{1 \_}$, $V_{2 \_}$, and $V_{3 \_\mathrm{C}}$ are the voltages of PV1, PV2, and $\mathrm{PV} 3$, respectively, at point $\mathrm{C}$; and $V_{\mathrm{d}}$ is the value of voltage drop of the blocking and bypass diodes.

$$
\begin{aligned}
V_{B}= & V_{1_{-} B}+V_{2_{-} B}+-2 V_{d} \\
= & C_{2} V_{O C} \ln \left(1+\frac{1}{C_{1}}\left(1-\frac{I_{B}-D I_{1}}{I_{S C}}\right)\right)+D V_{1} \\
& +C_{2} V_{O C} \ln \left(1+\frac{1}{C_{1}}\left(1-\frac{I_{B}-D I_{2}}{I_{S C}}\right)\right)+D V_{2} \\
& -2 V_{d}
\end{aligned}
$$

where $V_{1 \_\mathrm{B}}, V_{2 \_ \text {B }}$ are the voltages of PV1 and PV2 at point $B$, respectively.

$$
\begin{aligned}
V_{A}= & V_{1_{-} A}-3 V_{d} \\
= & C_{2} V_{O C} \ln \left(1+\frac{1}{C_{1}}\left(1-\frac{I_{A}-D I_{1}}{I_{S C}}\right)\right)+D V_{1} \\
& -3 V_{d}
\end{aligned}
$$

where $V_{1 \_\mathrm{A}}$ is the voltage of PV1 at point $A$.

Therefore, the voltage intervals between the three LMPPs are

$$
\begin{aligned}
V_{C_{-} B}= & V_{C}-V_{B} \\
= & C_{2} V_{O C} \ln \left(\frac{C_{1} I_{S C}+I_{S C}-I_{C}+D I_{1}}{C_{1} I_{S C}+I_{S C}-I_{B}+D I_{1}}\right) \\
& +C_{2} V_{O C} \ln \left(\frac{C_{1} I_{S C}+I_{S C}-I_{C}+D I_{2}}{C_{1} I_{S C}+I_{S C}-I_{B}+D I_{2}}\right) \\
& +C_{2} V_{O C} \ln \left(\frac{C_{1} I_{S C}+I_{S C}-I_{C}+D I_{3}}{C_{1} I_{S C}}\right)+D V_{3} \\
& +V_{d} \\
V_{B_{-} A}= & V_{B}-V_{A} \\
= & C_{2} V_{O C} \ln \left(\frac{C_{1} I_{S C}+I_{S C}-I_{B}+D I_{1}}{C_{1} I_{S C}+I_{S C}-I_{A}+D I_{1}}\right) \\
& +C_{2} V_{O C} \ln \left(\frac{C_{1} I_{S C}+I_{S C}-I_{B}+D I_{2}}{C_{1} I_{S C}}\right)+D V_{2} \\
& +V_{d}
\end{aligned}
$$

where $I_{\mathrm{A}}, I_{\mathrm{B}}$, and $I_{\mathrm{C}}$ are the currents of point $A, B, C$, and $I_{\mathrm{A}}>I_{\mathrm{B}}>I_{\mathrm{C}}$, thus,

$$
\ln \left(\frac{C_{1} I_{S C}+I_{S C}-I_{C}+D I_{1}}{C_{1} I_{S C}+I_{S C}-I_{B}+D I_{1}}\right)>0
$$




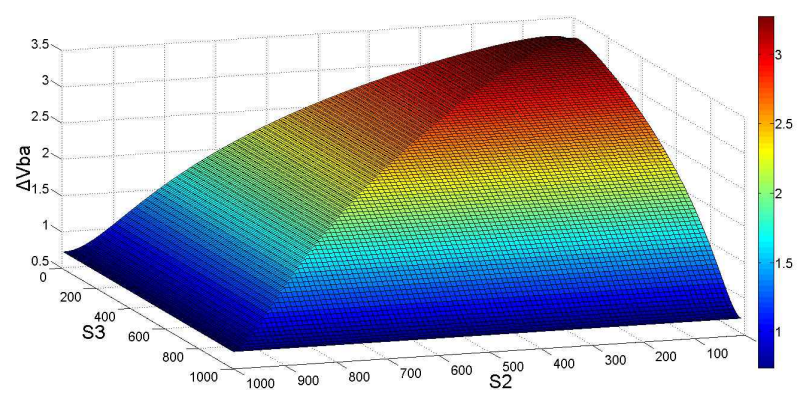

Fig. 5. Value of $V_{\mathrm{B}_{-} \mathrm{A}}-V_{\mathrm{B} \_\mathrm{MPP}}$

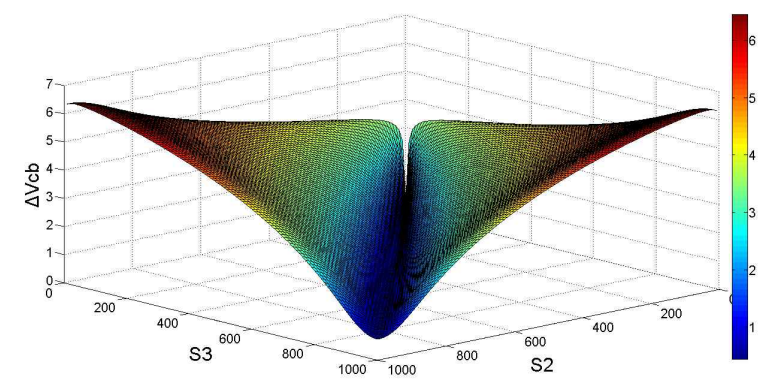

Fig. 6. Value of $V_{\mathrm{C}_{-} \mathrm{B}}-V_{\mathrm{C}_{-} \mathrm{MPP}}$.

$$
\begin{aligned}
& \ln \left(\frac{C_{1} I_{S C}+I_{S C}-I_{C}+D I_{2}}{C_{1} I_{S C}+I_{S C}-I_{B}+D I_{2}}\right)>0 \\
& \ln \left(\frac{C_{1} I_{S C}+I_{S C}-I_{B}+D I_{1}}{C_{1} I_{S C}+I_{S C}-I_{A}+D I_{1}}\right)>0
\end{aligned}
$$

According to single module operating under irradiance $\mathrm{S} 1$, $\mathrm{S} 2$, and S3, the voltages of the MPP are

$$
\begin{aligned}
V_{A_{-} M P P}= & \ln \left(\frac{C_{1} I_{S C}+I_{S C}-I_{A_{-} M P P}+D I_{1}}{C_{1} I_{S C}}\right) \\
& +D V_{1}-V_{d} \\
V_{B_{-} M P P}= & \ln \left(\frac{C_{1} I_{S C}+I_{S C}-I_{B_{-} M P P}+D I_{2}}{C_{1} I_{S C}}\right) \\
& +D V_{2}-V_{d} \\
V_{C_{-} M P P}= & \ln \left(\frac{C_{1} I_{S C}+I_{S C}-I_{C_{-} M P P}+D I_{3}}{C_{1} I_{S C}}\right) \\
& +D V_{3}-V_{d}
\end{aligned}
$$

Simulation is conducted to obtain the relationship between $V_{\mathrm{C}_{-} \mathrm{B}}$ and $V_{\mathrm{C} \_\mathrm{MPP}}$ and $V_{\mathrm{B}_{-} \mathrm{A}}$ and $\mathrm{V}_{\mathrm{B} \_ \text {MPP }}$ accurately. $\mathrm{S} 1$ is set at $1000 \mathrm{~W} / \mathrm{m}^{2} ; \mathrm{S} 2$ and $\mathrm{S} 3$ vary from $0 \mathrm{~W} / \mathrm{m}^{2}$ to $1000 \mathrm{~W} / \mathrm{m}^{2}$, and the results of $V_{\mathrm{B}_{-} \mathrm{A}}-V_{\mathrm{B}_{-} \mathrm{MPP}}$ and $V_{\mathrm{C}_{-} \mathrm{B}}-V_{\mathrm{C}_{-} \mathrm{MPP}}$ are shown in Figs. 5 and 6 . The open-circuit voltages of modules with irradiance $\mathrm{S} 2$ and S3 can be calculated by Eq. (7), with the value of $a$ for the selected PV module at 0.066 . The results of $V_{\mathrm{B}_{-} \mathrm{OC}}-V_{\mathrm{B}_{-} \mathrm{A}}$ and $V_{\mathrm{C}_{-} \mathrm{OC}}-V_{\mathrm{C}_{-} \mathrm{B}}$ are shown in Figs. 7 and 8 , respectively. $V_{\mathrm{B} \_\mathrm{OC}}$ and $V_{\mathrm{C} O C}$ are the open-circuit voltages of the modules with irradiance $\mathrm{S} 2$ and $\mathrm{S} 3$.

The mathematical deduction process and calculated results shown in Figs. 7 and 8 indicate that $V_{\mathrm{B}_{-} \mathrm{A}}$ is larger than $V_{\mathrm{B}_{-} \mathrm{MPP}}$,

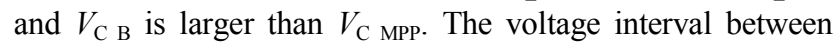
LMPPs on the $P-V$ curve of a single PV string shows that

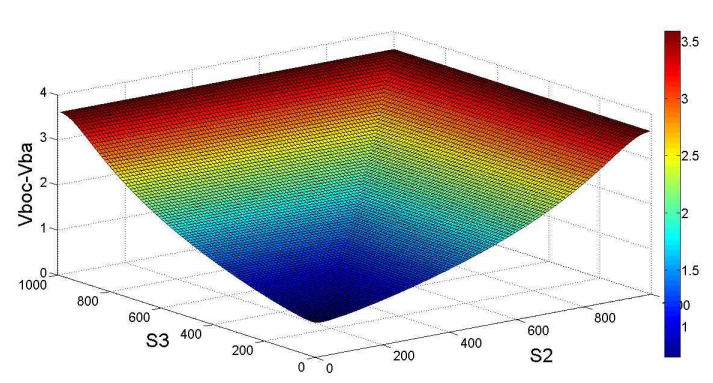

Fig. 7. Value of $V_{\mathrm{B} \_O C}-V_{\mathrm{B} \_\mathrm{A}}$.

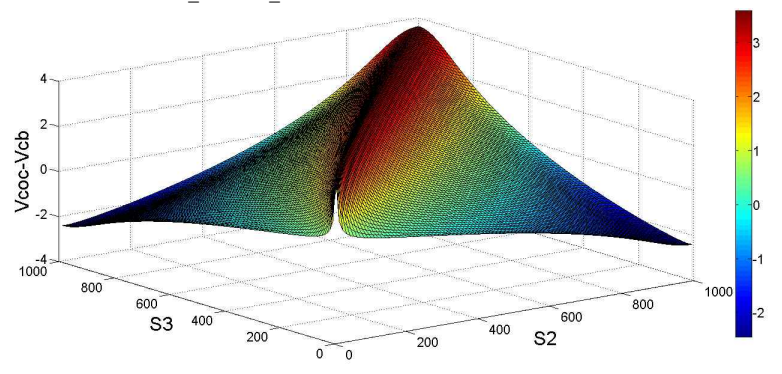

Fig. 8. Value of $V_{\mathrm{C} \_\mathrm{OC}}-V_{\mathrm{C} \_\mathrm{B}}$.

TABLE III

PV ARRAY UNDER DIFFERENT IRRADIANCE CONDITIONS

\begin{tabular}{lccc}
\hline \hline & PVM1 & PVM2 & PVM3 \\
\hline Condition 1 & $800 \mathrm{~W} / \mathrm{m}^{2}$ & $700 \mathrm{~W} / \mathrm{m}^{2}$ & $600 \mathrm{~W} / \mathrm{m}^{2}$ \\
Condition 2 & $800 \mathrm{~W} / \mathrm{m}^{2}$ & $700 \mathrm{~W} / \mathrm{m}^{2}$ & $500 \mathrm{~W} / \mathrm{m}^{2}$ \\
Condition 3 & $800 \mathrm{~W} / \mathrm{m}^{2}$ & $700 \mathrm{~W} / \mathrm{m}^{2}$ & $400 \mathrm{~W} / \mathrm{m}^{2}$ \\
Condition 4 & $800 \mathrm{~W} / \mathrm{m}^{2}$ & $600 \mathrm{~W} / \mathrm{m}^{2}$ & $400 \mathrm{~W} / \mathrm{m}^{2}$ \\
Condition 5 & $800 \mathrm{~W} / \mathrm{m}^{2}$ & $600 \mathrm{~W} / \mathrm{m}^{2}$ & $300 \mathrm{~W} / \mathrm{m}^{2}$ \\
Condition 6 & $800 \mathrm{~W} / \mathrm{m}^{2}$ & $600 \mathrm{~W} / \mathrm{m}^{2}$ & $200 \mathrm{~W} / \mathrm{m}^{2}$ \\
\hline \hline
\end{tabular}

$V_{\mathrm{B}_{-} \mathrm{OC}}$ and $V_{\mathrm{C} \_\mathrm{OC}}$ are larger than $V_{\mathrm{B} \_\mathrm{A}}$ and $V_{\mathrm{C}_{-} \mathrm{B}}$ in most cases. The conclusion above fails when either $\mathrm{S} 2$ or $\mathrm{S} 3$ is less than $\mathrm{S} 1$. However, the irradiance conditions that caused the will almost not occur in actual application. When all the above-mentioned factors are considered, the voltage interval is less than the open-voltage of a bypass diode area and greater than the voltage of MPP of the module operating independently.

\section{Voltage Interval between LMPPS}

The simulation is established and the array structure configuration is formed by three modules in series to verify the result derived above. Temperature is set to $25{ }^{\circ} \mathrm{C}$ under all conditions. Six different conditions of PV array are shown in Table III. The voltage value of LMPPs for the different conditions is shown correspondingly in Table IV.

$\Delta V_{1-2}$ is the voltage interval between $V_{\mathrm{LMPP} 1}$ and $V_{\mathrm{LMPP} 2}$, and $\Delta V_{2-3}$ is the voltage interval between $V_{\mathrm{LMPP} 2}$ and $V_{\mathrm{LMPP} 3}$.

Considering real environment conditions, the influence of the PV modules' temperature on open-circuit voltage cannot be ignored. The PV array operates under conditions 7-11, and 
TABLE IV

VOLTAGE OF LMPP AND THE VOLTAGE INTERVAL BETWEEN LMPPS

\begin{tabular}{lllrl}
\hline \hline$V_{\mathrm{LMPP} 1}$ & $V_{\mathrm{LMPP} 2}$ & $V_{\mathrm{LMPP} 3}$ & $\Delta V_{1-2}$ & $\Delta V_{2-3}$ \\
\hline 54.08 & $35.12 \mathrm{~V}$ & $16.58 \mathrm{~V}$ & $18.96 \mathrm{~V}$ & 18.54 \\
$\mathrm{~V}$ & & & & $\mathrm{~V}$ \\
55.13 & $35.12 \mathrm{~V}$ & $16.58 \mathrm{~V}$ & $20.01 \mathrm{~V}$ & 18.54 \\
$\mathrm{~V}$ & & & & $\mathrm{~V}$ \\
55.83 & $35.12 \mathrm{~V}$ & $16.58 \mathrm{~V}$ & $20.71 \mathrm{~V}$ & 18.54 \\
$\mathrm{~V}$ & & & & $\mathrm{~V}$ \\
55.17 & $35.40 \mathrm{~V}$ & $16.58 \mathrm{~V}$ & $19.77 \mathrm{~V}$ & 18.82 \\
$\mathrm{~V}$ & & & & $\mathrm{~V}$ \\
55.64 & $35.40 \mathrm{~V}$ & $16.58 \mathrm{~V}$ & $20.24 \mathrm{~V}$ & 18.82 \\
$\mathrm{~V}$ & & & & $\mathrm{~V}$ \\
55.84 & $35.40 \mathrm{~V}$ & $16.58 \mathrm{~V}$ & $20.44 \mathrm{~V}$ & 18.82 \\
$\mathrm{~V}$ & & & & $\mathrm{~V}$ \\
\hline \hline
\end{tabular}

TABLE V

VOLTAGE OF LMPP AND THE VOLTAGE INTERVALS BETWEEN LMPPS UNDER CONDITIONS 7-11

\begin{tabular}{lccccccl}
\hline \hline \multicolumn{2}{c}{$V_{\mathrm{LMPP}}$} & $V_{\mathrm{LMPP}}$ & $V_{\mathrm{LMPP}}$ & $\Delta V_{1-2}$ & $\Delta V_{2-3}$ & $V_{\mathrm{MPP}}$ & $V_{\mathrm{OC}}$ \\
\hline 7 & 57.28 & 36.90 & 17.27 & 20.38 & 19.63 & 18.17 & 22.3 \\
& & & & & & & 2 \\
8 & 55.17 & 35.40 & 16.58 & 19.77 & 18.82 & 17.39 & $\begin{array}{l}21.6 \\
\end{array}$ \\
9 & 53.05 & 34.19 & 15.89 & 18.86 & 18.30 & 17.07 & 20.8 \\
& & & & & & & 7 \\
1 & 50.92 & 32.69 & 15.54 & 18.23 & 17.15 & 16.29 & 20.1 \\
0 & & & & & & & 5 \\
1 & 48.78 & 31.18 & 14.50 & 17.60 & 16.68 & 15.50 & 19.4 \\
1 & & & & & & & 2 \\
\hline \hline
\end{tabular}

three modules receive the fixed incidence irradiance $(\mathrm{S} 1=800$ $\mathrm{W} / \mathrm{m}^{2}, \mathrm{~S} 2=600 \mathrm{~W} / \mathrm{m}^{2}, \mathrm{~S} 3=400 \mathrm{~W} / \mathrm{m}^{2}$ ). The temperature of all modules under different conditions escalates. The temperatures from conditions $7-11$ are $15,25,35,45$, and $55^{\circ} \mathrm{C}$. The $I-V$, $P-V$ curves of PV array and voltage value of LMPPs are obtained from the simulation, as shown in Fig. 9. The voltage interval can be calculated from the voltages of LMPPs. The MPP and open-circuit voltages of the module are presented in Table $\mathrm{V}$, with voltage denoted as $\mathrm{V}$.

$V_{\mathrm{MPP}}$ and $V_{\mathrm{OC}}$ are respectively the voltage of MPP and open circuit of a single module under uniform condition of different temperatures.

Fig. 9 shows that the higher temperature of PV array results in a lower open-circuit voltage and a higher short-circuit current. LMPPs also correspond to the change in temperature.

Although the irradiance of each module received is different, the voltage interval between LMPPs on the $P-V$ curve decreases with the increment of temperature, as shown in Table

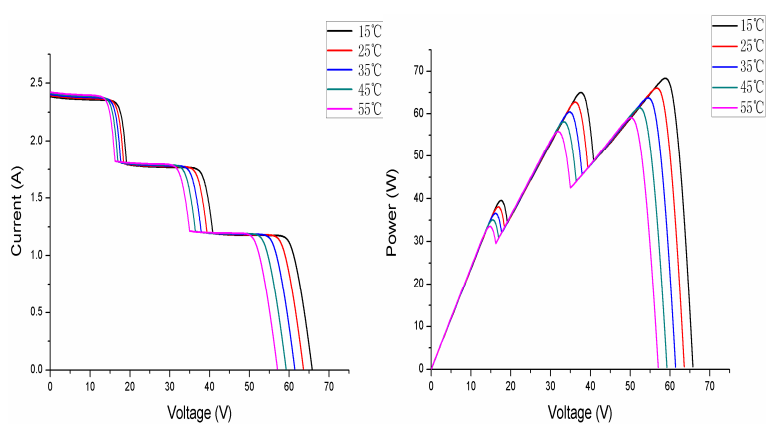

Fig. 9. Relationship of voltages between LMPPs.

$\mathrm{V}$. The value of the voltage interval remains within the range of $V_{\mathrm{MPP}}$ to $V_{\mathrm{OC}}$ even as it changes with the module temperature.

\section{PROPOSED GMPPT ALGORITHM}

\section{A. Control Process of GMPPT Algorithm}

The proposed GMPPT algorithm is based on the mathematical derivation of voltage interval between LMPPs, as described in Section II. The value of voltage interval is less than the open-circuit voltage and greater than the MPP voltage under the same operating condition.

The global searching is divided into four steps:

Step 1: The first MPP (possibly the LMPP) is searched through fine search in the high voltage range. The power and voltage values of this peak point are saved. The fine search depends on the $\mathrm{P} \& \mathrm{O}$ searching algorithm.

Step 2: The searching point moves to the vicinity of the next LMPP with voltage interval, and the value of $\mathrm{dP} / \mathrm{dV}$ is calculated; if the value is greater than zero, the searching point moves to the vicinity of the next LMPP, else the fine search algorithm is employed.

Step 3: The fine search is employed to obtain the LMPP. The power and voltage values of this point are saved and then the power of the new LMPP is compared with the power of the last LMPP, save the greater one.

Step 4: Steps 1 to 3 are repeated. When the searching voltage is less than $V_{\min }$, the GMPPT algorithm search is stopped. All LMPPs have been searched with the voltage interval, and the power and voltage values of GMPP are saved.

The process of the GMPPT algorithm is shown in Fig. 10.

\section{B. Key Algorithm Parameters}

The selection value of the voltage interval between two adjacent LMPPs determines the accuracy and speed of the GMPPT algorithm during the entire process. The value is less than the open-circuit voltage and greater than the MPP voltage of module in a bypass diode area. For practical application, the measurement of each module's open-circuit voltage needs a large number of additional sensors and therefore unfeasible. In most cases (irradiance is more than $300 \mathrm{~W} / \mathrm{m}^{2}$ ), as shown in Fig.2, the open-circuit voltage changes little with irradiance; thus, voltage interval is set as 


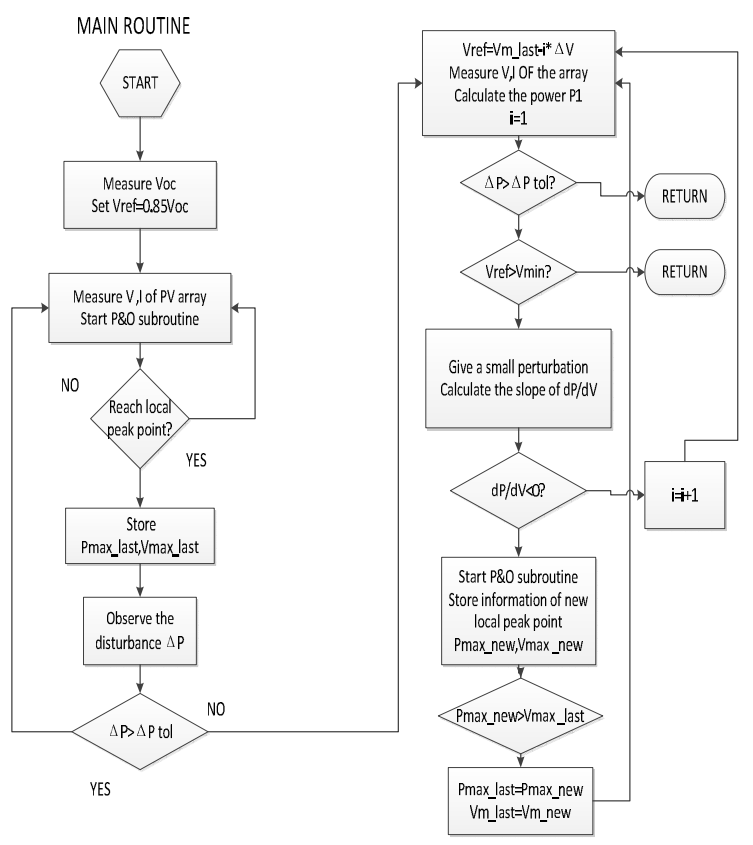

Fig. 10. GMPPT algorithm process.

$$
\Delta V \in\left[V_{M P P(S T C)}, V_{O C(S T C)}\right]
$$

To determine voltage interval $\Delta V$, the influence of the module's temperature for open-circuit voltage should be considered in [20]

$$
V_{O C}^{\prime}=\left[1+\beta\left(T-T_{r e f}\right)\right] V_{O C(S T C)}
$$

The MPP voltage of the module in a bypass diode area is approximately $80 \%$ of the open-circuit voltage

$$
\begin{aligned}
& V_{M P P}^{\prime}=0.8 V_{O C}^{\prime} \\
& \Delta V \in\left[V_{M P P}^{\prime}, V_{O C}^{\prime}\right]
\end{aligned}
$$

Each target point must be secured after moving to the right side of the LMPP and then combined with observations in Figs. 7 and 8 , such that the voltage interval can be set as the average of $V_{\text {MPP }}^{\prime}$ and $V^{\prime}$ OC

$$
\Delta V \approx 0.9 V_{O C}^{\prime}
$$

This value is applicable in most common conditions in Tables IV and V, but may fail in severely mismatch conditions. In the PV array application, searching the minimum voltage $V_{\min }$ is set at half of the open-circuit voltage of a PV module in STC because the voltage of the GMPP is more than half of the rating working voltage of one bypass diode area.

\section{Illustration of the GMPPT Algorithm}

Fig. 11 shows that $P 1$ is the first LMPP searched by this algorithm, $B$ is the operating point after first moving, and $A$ is the next LMPP searched. The controller moves from $P 1$ to $B$ with the voltage interval directly. The operating point located at the right side of the next LMPP as $B$ is shown in Fig. 12 . Two duty ratio disturbances are given when the controller operates at $B$. The sampling data calculated by the controller

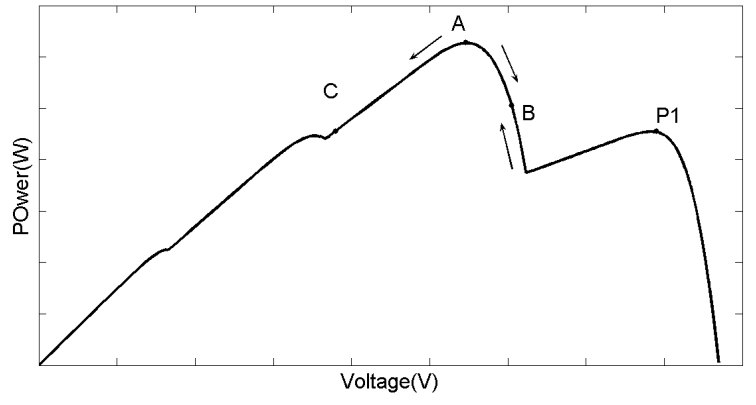

Fig. 11. Searching local peak points.

show $\mathrm{dP} / \mathrm{dV}<0$, and $A$ is searched by the $\mathrm{P} \& \mathrm{O}$ search algorithm.

$C$ is the next operating point moving from $A$, with $C$ located at the right side of the next LMPP. The sampling data calculated after two disturbances show $\mathrm{dP} / \mathrm{dV}>0$, which controller regards as having no target LMPP near $C$ (or target LMPP is insignificant). The controller stops the fine search and then moves to the next possible target point directly.

\section{Simulation Results AND EXPERIMENTAL ANALYSIS OF THE GMPPT ALGORITHM}

\section{A. Simulation and Results}

Three PV modules are connected in series. Though each module has two bypass diode areas, according to previous inference, the $P-V$ curve of the PV string has three LMPPs under three different irradiance levels. The irradiance levels of six bypass diodes areas are set as 400 and $600 \mathrm{~W} / \mathrm{m}^{2}$, with the rest at $800 \mathrm{~W} / \mathrm{m}^{2}$. The temperature of the modules is $40{ }^{\circ} \mathrm{C}$. The parameters of the simulated module are listed in Table I. As calculated by Eqs. (11) to (14), the open-circuit voltage of a bypass diode area is approximately $10.5 \mathrm{~V}$; the voltage of MPP is $8.4 \mathrm{~V}$; and the voltage interval from one LMPP to the next LMPP can be set at $9.4 \mathrm{~V}$. The simulation module is shown in Fig. 12. The last four irradiance levels are the same, to simplify the model, they are divided into two groups. Fig. 13 shows the connection of PV string. The irradiance of Cell1 and Cell2 is respectively $400 \mathrm{~W} / \mathrm{m}^{2}, 600 \mathrm{~W} /$ $\mathrm{m}^{2}$, and Cell3,Cell4 are incorporated by two bypass diode areas of $800 \mathrm{~W} / \mathrm{m}^{2}$.

The electrical characteristics of the LMPPs are shown in Table VI, and the $I-V$ and $P-V$ curves of the PV string are plotted in Fig. 14 correspondingly. The curves of the output voltage, current, and power versus simulation time are shown in Fig. 15. The controller starts GMPPT from $0.1 \mathrm{~s}$, and LMPPs are found at $0.35,0.55$, and $0.65 \mathrm{~s}$, respectively. The point at $0.55 \mathrm{~s}$ is optimum. The controller continues moving to the next possible LMPP at $0.7 \mathrm{~s}$ given that the operating voltage does not reach minimum voltage of the GMPPT search range. The controller does not search any local peak 


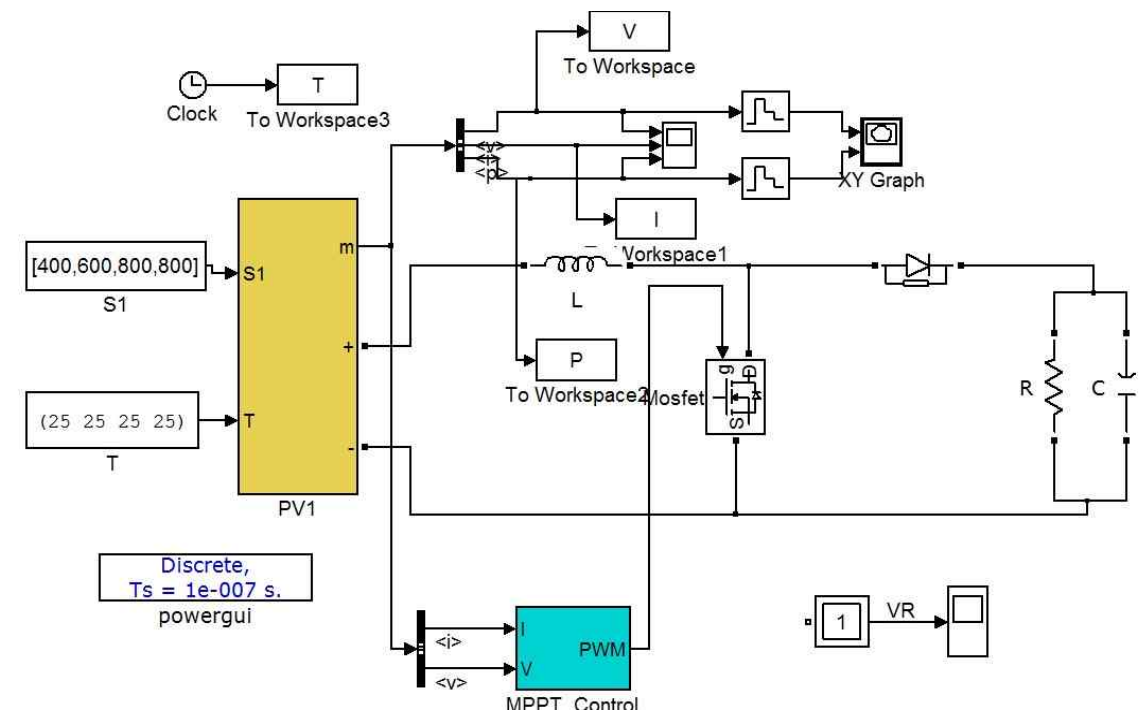

Fig. 12. Simulation model.

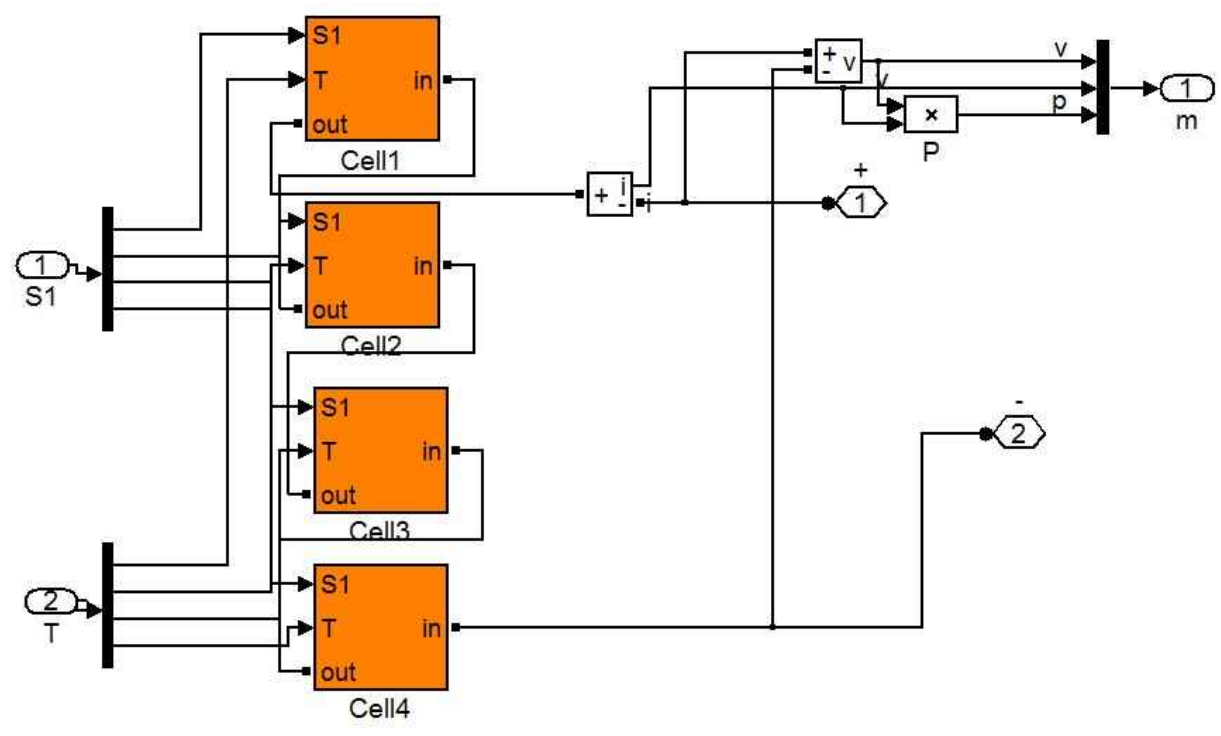

Fig. 13. Diagram of PV modules connected in series.

points after $0.7 \mathrm{~s}$ and returns to the known optimum point, i.e., GMPP, and remains stable.

The conventional hill-climbing method is compared with the proposed method through simulation under similar simulation conditions. The comparison is shown in Fig. 16, with the GMPP of the conventional hill-climbing method stable at $0.97 \mathrm{~s}$ and the GMPP of the proposed method stable at $0.83 \mathrm{~s}$; thus, the hill-climbing method consumed more time than the proposed method. When PV array operates at GMPP, the oscillation of the proposed method is less than the hill-climbing method, as shown in Fig. 16.

\section{B. Experiment and Results}

The experiment with a DSP-controlled DC/DC boost converter is implemented based on the model shown in Fig. 12 to verify the proposed algorithm.
TABLE VI

ELECTRICAL CHARACTERISTICS OF LMPPS IN THE SiMULATION

\begin{tabular}{llll}
\hline \hline & \multicolumn{3}{l}{$\begin{array}{l}\text { Electrical Characteristics of local peak } \\
\text { points }\end{array}$} \\
\cline { 2 - 4 } & $V(\mathrm{~V})$ & $I(\mathrm{~A})$ & $P(\mathrm{~W})$ \\
\hline MPP1 & 54.88 & 1.18 & 64.73 \\
MPP2 & 43.61 & 1.78 & 76.85 \\
MPP3 & 32.58 & 2.19 & 71.47 \\
GMPP & 43.61 & 1.78 & 76.85 \\
\hline \hline
\end{tabular}

In the experiment, three modules are connected in series and each module is covered with translucent membrane to produce different irradiance levels. The PV array controller is set as a tracer and the RS485 serial ports and PC monitoring interface are used for communication and data storing, with the data containing array voltage, current, and power transmitted every $10 \mathrm{~ms}$. 


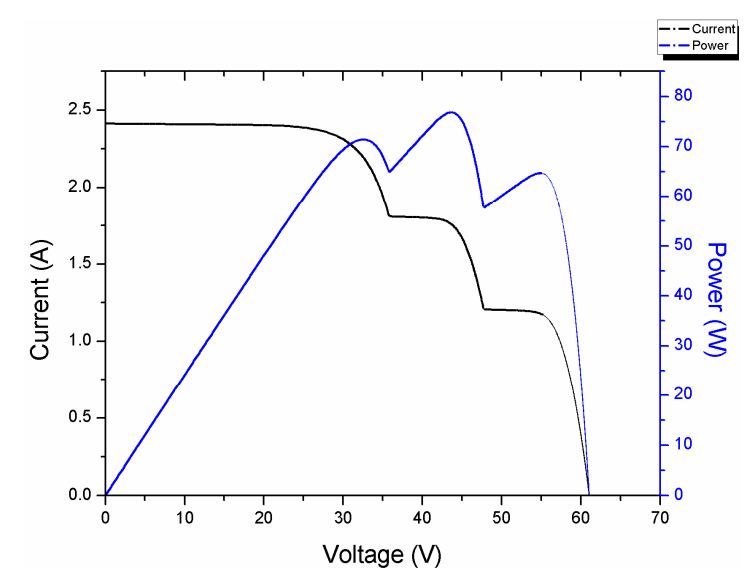

Fig. 14. Simulation curves of $V-I$ and $V-P$.
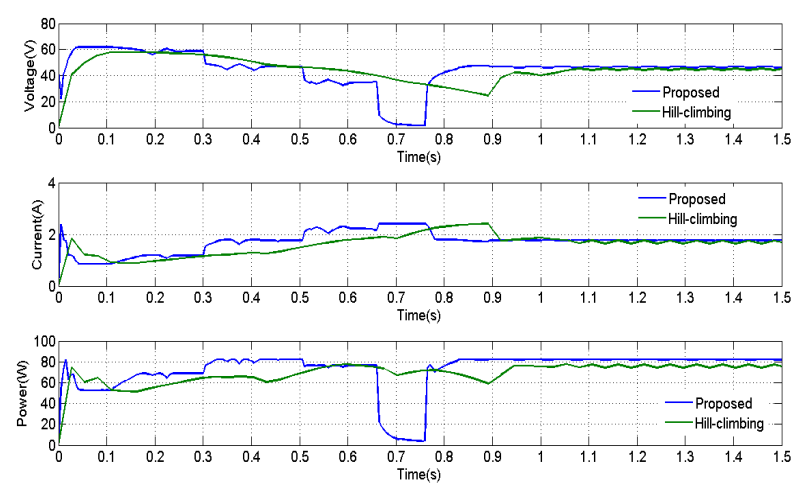

Fig. 15. Comparison of the proposed method and hill-climbing method.

\section{TABLE VII}

The Caption must be Followed by the Table

\begin{tabular}{|c|c|c|c|c|c|c|c|}
\hline & \multicolumn{3}{|c|}{ Measured data } & \multicolumn{2}{|c|}{ Traced data } & & \multirow[t]{2}{*}{$\begin{array}{l}\text { Power } \\
\text { error }(\%)\end{array}$} \\
\hline & $\overline{V / \mathrm{V}}$ & $I / \mathrm{A}$ & $P / \mathrm{W}$ & $V / \mathrm{V}$ & I/A & $P / \mathrm{W}$ & \\
\hline MPP1 & 54.4 & 1.28 & 69.8 & 54.5 & 1.29 & 70.5 & 0.993 \\
\hline MPP2 & 41.9 & 2.19 & 92.0 & 41.6 & 2.23 & 92.7 & 0.755 \\
\hline MPP3 & 30.6 & 2.59 & 79.4 & 31.32 & 2.57 & 80.5 & 1.366 \\
\hline GMPP & P41.35 & 2.22 & 92.0 & 40.5 & 2.27 & 92.7 & 0.755 \\
\hline
\end{tabular}

Fig. 17 demonstrates that the controller starts searching at $0.1 \mathrm{~s}$. The LMPPs are searched at approximately $0.15,0.5$, and $0.7 \mathrm{~s}$. No LMPPs were found in the subsequent search process. Fig.16 shows that the power of the second LMPP is the largest at approximately $90 \mathrm{~W}$, and controller operates stably at the second LMPP.

After the controller operated stably at GMPP, the electrical load was applied to the scan $I-V$ curve immediately, and measured curve is shown in Fig. 16. The measured powers of each LMPP are compared with the traced ones in Table VII, and the errors are acceptable.

The results of the simulation and the experiment demonstrate that the proposed GMPPT algorithm is fast and accurate.

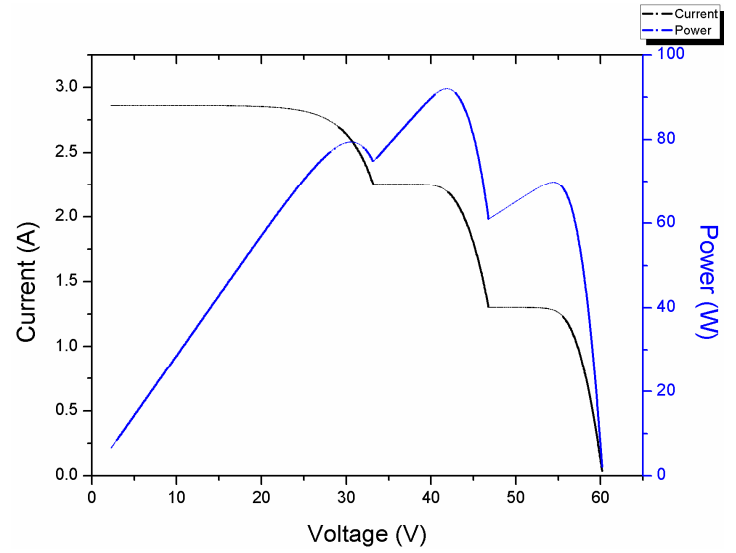

Fig. 16. Experiment curves of $V-I$ and $V-P$.
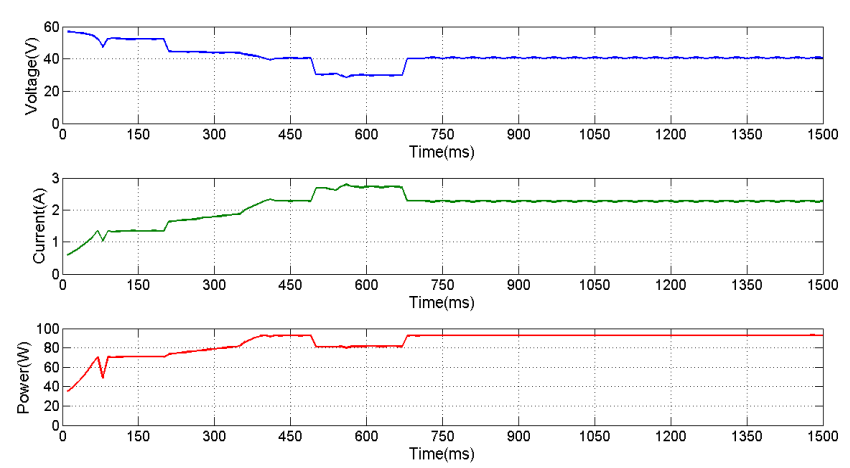

Fig. 17. Experiment tracking curves.

\section{CONCLUSIONS}

This study proposed an improved search algorithm based on voltage interval. This algorithm is simple and easy to implement. The voltage of the operating point is updated by the last LMPP, and the search is performed more accurately. This algorithm also can search for the GMPP without scanning the entire $P-V$ curve because the operating voltage is above $\mathrm{V}$ min. The proposed algorithm only searches from the right side to the left one at a time. The simulation and experimental results show that the proposed algorithm can track the GMPP of PV array accurately with significantly improved dynamic performance.

\section{ACKNOWLEDGEMENTS}

This work was supported by the Natural Science Foundation of Jiangsu Province under Grant No. BK20131134 and Changzhou Key Laboratory of Photovoltaic System Integration and Production Equipment Technology, Jiangsu, China.

\section{REFERENCES}

[1] C. Dorofte, U. Borup, and F. Blaabjerg, "A combined two-method MPPT control scheme for grid-connected 
photovoltaic systems," in Proc. Eur.Conf. Power Electron. Appl., pp. 1-10, 2005.

[2] N. Fernia, G. Petrone, G. Spagnuolo, and M. Vitelli, "Optimization of perturb and observe maximum power point tracking method," IEEE Trans. Power Electron. Vol. 20, No. 4, pp. 963-973, Jul. 2005.

[3] L. Piegari and R. Rizzo, "Adaptive perturb and observe algorithm for photovoltaic maximum power point tracking," IET Renewable Power Generation, Vol. 4, No. 4, pp. 317-328, Jul. 2010.

[4] J. Li and H. Wang, "A novel stand-alone PV generation system based on variable step size INC MPPT and SVPWM control," Power Electronics and Motion Control Conference, 2009. IPEMC '09. IEEE 6th International, pp. 2155-2160, 2009.

[5] Q. Fu and N. Tong, "A new fuzzy control method based on PSO for Maximum Power Point Tracking of photovoltaic system," Computer Science and Network Technology (ICCSNT), 2011 International Conference on, Vol. 3, pp. 1487,1491, 2011.

[6] N. D. Kaushika and N. K. Gautam, "Mismatch losses and time to failure of solar PV arrays," in Proc. international solar energy society meeting, pp. 1681-1686, 2001.

[7] T. Shimizu, M. Hirakata, T. Kamezawa T, and H. Watanabe, "Generation control circuit for photovoltaic modules," IEEE Trans. Power Electron., Vol. 16, No. 3, pp. 293-300, May 2001.

[8] T. Mishima and T. Ohnishi, "A power compensation strategy based on electric double layer capacitors for a partially shaded PV array," Power Electronics and Drive Systems, 2003. PEDS 2003. The Fifth International Conference on. IEEE, pp. 858-863, Feb. 2003.

[9] W. Xiao, N. Ozog, and W. G. Dunford, "Topology study of photovoltaic interface for maximum power point tracking," IEEE Trans. Ind. Electron., Vol. 54, No. 3, pp. 1696-1704, Jun. 2007.

[10] A. Bidram, A. Davoudi, and R. S. Balog, "Control and circuit techniques to mitigate partial shading effects in photovoltaic arrays," IEEE J. Photovoltaic, Vol. 2, No. 4, pp. 532-546, Oct. 2012.

[11] K. Ishaque and Z. Salam, "A deterministic particle swarm optimization maximum power point tracker for photovoltaic system under partial shading condition," IEEE Trans. Ind. Appl., Vol. 60, No. 8, pp. 3195-3206, Aug. 2013.

[12] H. Shi, S. Zhao, and J. Wen, "An improved particle swarm optimization for pre-denoise at the exhaust pipeline design stage," 2008 IEEE International Conference on Industrial Engineering and Engineering Management, pp. 780-784, 2008.

[13] K. Kobayashi, I. Takano, and Y. Sawada, "A study on a two stage maximum power point tracking control of a photovoltaic system under partially shaded insolation conditions," Solar energy materials and solar cells, Vol. 90, No. 18, pp. 2975-2988, Nov. 2006.

[14] A. Kajihara and A. T.Harakawa, "Model of photovoltaic cell circuits under partial shading," IEEE International Conference on Industrial Technology Hong Kong, pp. 866-870, 2005.

[15] M. Miyatake, T. Inada, I. Hiratsuka, H. Zhao, H. Otsuka, and M. Nakano, "Control characteristics of a
Fibonacci-search-based maximum power point tracker when a photovoltaic array is partially shaded," in Proc. IEEE IPEMC, Vol. 2, pp. 816-821, 2004.

[16] H. Patel and V. Agarwal, "Maximum power point tracking scheme for PV systems operating under partially shaded conditions," IEEE Trans. Ind. Electron., Vol. 55, No. 4, pp. 1689-1698, Apr. 2008.

[17] W. De Soto, S. A. Klein, and W. A. Beckman, "Improvement and validation of a model for photovoltaic array performance," Solar Energy, Vol. 80, No. 1, pp. 78-88, Jan. 2006.

[18] W. Kim and W. Choi, "A novel parameter extraction method for the one-diode solar cell model," Solar Energy, Vol. 84, No. 6, pp. 1008-1019, Jun. 2010.

[19] H. Tian, F. Mancilla-David, K. Ellis, E. Muljadi, and P. Jenkins, "A cell-to-module-to-array detailed model for photovoltaic panels," Solar Energy, Vol. 86, No. 9, pp. 2695-2706, Sep. 2012.

[20] K. Ding, X. G. Bian, H. H. Liu, and T. Peng, "A MATLAB-simulink-based PV module model and its application under conditions of nonuniform irradiance," IEEE Trans. Energy Convers., Vol. 27, No. 4, pp. 864-872, Dec. 2012.

[21] M. Mao, S. Yu, and J. Su, "Versatile matlab simulation model for photovoltaic array with MPPT function," Acta Simulata Systematica Sinica, Vol. 5, pp. 1248-1251, May 2005.

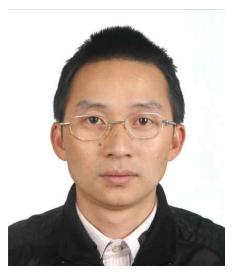

Kun Ding received an MS degree in Materials Processing Engineering and a Ph.D. degree in Electrical Engineering from Hohai University, Jiangsu, China, in 2000 and 2009, respectively. $\mathrm{He}$ is currently an Associate Professor at the College of Mechanical and Electrical Engineering, Hohai University. His research interests include the areas of power conversion and control for renewable energy interface, especially photovoltaic (PV), PV array configuration, PV system design, and $\mathrm{dc}-\mathrm{dc}$ converters.

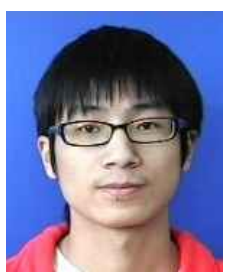

Xiang Wang is currently working toward a Master's degree at the College of Mechanical and Electrical Engineering, Hohai University, Jiangsu, China. His research interests include the areas of DSP-based control and grid-connected converter of photovoltaic (PV) modules in distributed PV system.

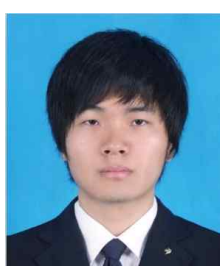

Quan-Xin Zhai is currently working toward a Master's degree at the College of Mechanical and Electrical Engineering, Hohai University, Jiangsu, China. 


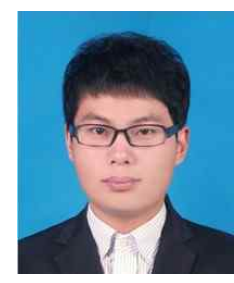

Jun-Wei Xu was born in Suzhou, Jiangsu, China in 1989 . He is currently a candidate for a master's degree at the College of Mechanical \& Electrical Engineering, Hohai University, Changzhou, Jiangsu, China.

$\mathrm{He}$ is researching PV array topology reconfiguration.

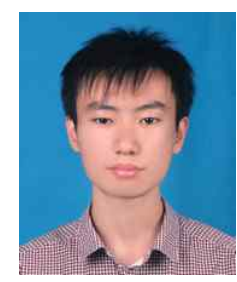

Jing-Wei Zhang was born in Nanjing, Jiangsu, China in 1989. Currently, he is a candidate for a master's degree at the College of Mechanical \& Electrical Engineering, Hohai University, Changzhou, Jiangsu, China. His research interests include modeling and simulation of the electrical characteristics of PV modules, development of outdoor test platform, and power estimation of PV systems.

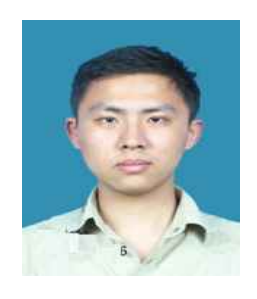

Hai-Hao Liu was born in NanJing, Jiangsu, China in 1987. He received a master's degree in 2012 from the College of Mechanical \& Electrical Engineering, Hohai University, Changzhou, Jiangsu, China. His research interessts include DC converters based on DSP control and its control for photovoltaic applications. 